\title{
Validation of a simple dynamic thermal performance characterization model based on the piston flow concept for flat-plate solar collectors
}

Deng, Jie; Yang, Ming; Ma, Rongjiang; Zhu, Xiaolin; Fan, Jianhua; Yuan, Guofeng; Wang, Zhifeng

Published in:

Solar Energy

Link to article, DOI:

10.1016/j.solener.2016.09.040

Publication date:

2016

Document Version

Peer reviewed version

Link back to DTU Orbit

Citation (APA):

Deng, J., Yang, M., Ma, R., Zhu, X., Fan, J., Yuan, G., \& Wang, Z. (2016). Validation of a simple dynamic thermal performance characterization model based on the piston flow concept for flat-plate solar collectors. Solar Energy, 139, 171-178. https://doi.org/10.1016/j.solener.2016.09.040

\section{General rights}

Copyright and moral rights for the publications made accessible in the public portal are retained by the authors and/or other copyright owners and it is a condition of accessing publications that users recognise and abide by the legal requirements associated with these rights.

- Users may download and print one copy of any publication from the public portal for the purpose of private study or research.

- You may not further distribute the material or use it for any profit-making activity or commercial gain

- You may freely distribute the URL identifying the publication in the public portal 
Validation of a simple dynamic thermal performance characterization model based on the piston flow concept for flat-plate solar collectors

Jie Deng a, b,", Ming Yang a, Rongjiang Ma ${ }^{\mathrm{c}}$, Xiaolin Zhu ${ }^{\mathrm{a}}$, Jianhua Fan ${ }^{\mathrm{b}}$, Guofeng Yuan ${ }^{\text {a, b }}$, Zhifeng Wang a, d

${ }^{a}$ Key Laboratory of Solar Thermal Energy and Photovoltaic System, Institute of Electrical Engineering, Chinese Academy of Sciences, Beijing100190, PR China

${ }^{\mathrm{b}}$ Department of Civil Engineering, Technical University of Denmark, Brovej 118, Kgs. Lyngby, DK 2800, Denmark

${ }^{\mathrm{c}}$ Department of Building Science, Tsinghua University, Beijing 100084, PR China

${ }^{\mathrm{d}}$ Beijing Engineering Research Center of Solar Thermal Power, Beijing100190, PR China

* Corresponding author:

Institute of Electrical Engineering, Chinese Academy of Sciences, Beijing 100190, China

Tel.: +861082547266

Fax: +861062587946

E-mail address: deng-jie2@163.com (J. Deng) 


\section{Validation of a simple dynamic thermal performance characterization model based on the piston flow concept for flat-plate solar collectors}

\section{Abstract}

A simple dynamic characterization model of flat-plate solar collectors based on the piston flow concept is used both to identify the collector characteristic parameters and to predict the dynamic thermal performance. The heat transport time originally defined as $\left(1-e^{-1}\right)^{-1} \tau_{C}$ by Amrizal et al. (2012) for the model turns out to be the collector static response time constant $\tau_{C}$ by analytical derivation. The nonlinear least squares method is applied to determine the characteristic parameters of a flat-plate solar air collector previously tested by the authors. Then the obtained parameters are used to predict the dynamic behavior of the collector outlet temperature. The model coefficients particularly $c_{3}$ in the simple dynamic characterization model are examined by the collector dynamic prediction under variable meteorological conditions. Meanwhile, the prediction accuracy of the simple dynamic model based on the first-order difference method is compared to that of the numerical solution of the collector ordinary differential equation (ODE) model using the fourth-order Runge-Kutta method. The improved thermal inertia model (TIM) on the basis of closed-form solution presented by Deng et al. (2016a) is also considered. The results show that the prediction performance of the simple dynamic model is nearly as accurate as the ODE numerical solution and the TIM by Deng et al. (2016a) 
except some special conditions such as sharply changed solar irradiance and collector inlet temperature.

Keywords: Flat-plate solar collector; Dynamic thermal performance model; Piston flow concept; Ordinary differential equation (ODE) 


\section{List of symbols}

\section{Nomenclature}

$A_{a} \quad$ collector aperture area, $\mathrm{m}^{2}$

$A_{g} \quad$ gross collector area, $\mathrm{m}^{2}$

$A_{\text {seg }} \quad$ segment area of the collector, $\mathrm{m}^{2}$

$c_{1}-c_{3}$ model coefficients: $c_{1},\left(\mathrm{~m}^{2} \mathrm{~K}\right) / \mathrm{W} ; c_{2}$ and $c_{3}$, dimensionless

$c_{f} \quad$ specific heat of the working fluid, $\mathrm{J} /(\mathrm{kg} \mathrm{K})$

$F^{\prime} \quad$ solar collector flow efficiency factor, dimensionless

$F_{R} \quad$ solar collector heat removal factor, dimensionless

$G_{g} \quad$ global solar irradiance on the collector surface, $\mathrm{W} / \mathrm{m}^{2}$

$K_{\theta}(\theta) \quad$ collector incidence angle modifier, dimensionless

$M \quad$ number of the test data sequence, dimensionless

$\dot{m}_{f} \quad$ mass flow rate of the working fluid, $\mathrm{kg} / \mathrm{s}$

$(M c)_{e} \quad$ effective thermal capacity of solar collector, $\mathrm{J} / \mathrm{K}$

$(m c)_{\text {seg }}$ thermal capacity of the solar collector segment, $\mathrm{J} / \mathrm{K}$

$N \quad$ collector segment number, dimensionless

$n \quad$ time step number, dimensionless

$T \quad$ characteristic temperature of the collector working fluid, ${ }^{\circ} \mathrm{C}$

$T_{0} \quad$ fluid temperature at the entrance of the segment, ${ }^{\circ} \mathrm{C}$

$T_{a} \quad$ ambient temperature, ${ }^{\circ} \mathrm{C}$

$T_{f i} \quad$ collector inlet temperature, ${ }^{\circ} \mathrm{C}$

$T_{f o} \quad$ collector outlet temperature, ${ }^{\circ} \mathrm{C}$

$T_{i x}^{i t} \quad$ fluid temperature at the ' $i x$-th' segment and the ' $i t$-th' time step, ${ }^{\circ} \mathrm{C}$

$U_{L} \quad$ total heat loss coefficient of the solar collector, $\mathrm{W} /\left(\mathrm{m}^{2} \mathrm{~K}\right)$

Greek symbols

$\alpha \quad$ absorptance, dimensionless

$\Delta \tau \quad$ time interval, $\mathrm{s}$ 
$\tau \quad$ time, s; transmittance of glass cover, dimensionless

$\tau_{C} \quad$ collector static response time constant, $\mathrm{s}$

$\tau_{t} \quad$ collector heat transport time for the simple dynamic model in Equation (6), $\mathrm{s}$

$(\tau \alpha)_{e n}$ effective transmittance-absorptance product at normal incidence, dimensionless

Subscript

a ambient

$f i \quad$ working fluid inlet

fo $\quad$ working fluid outlet

it time step

ix $\quad$ spatial step 


\section{Introduction}

Flat-plate solar collectors are widely used in the field of low-temperature solar thermal utilization. Figure 1(a), (b) show the schematic illustration of the typical types of single glass flat-plate solar collectors with water/antifreeze fluid and air as working fluid respectively. Characterization model of dynamic thermal performance of flat plate solar collectors is a key problem in the collector thermal performance test and prediction under variable meteorological conditions for real engineering. From the viewpoint of applicability, it is desired to have a characterization model which can both determine the collector characteristic parameters via dynamic tests and predict the collector dynamic thermal performance with given meteorological and operating conditions using the obtained parameters. However, previous studies usually focused on the collector dynamic test and prediction independently. Generally speaking, there are two categories of characterization models for the flat plate solar collectors: physical models and non-physical models. Examples of the non-physical models are collector dynamic models based on artificial neural network (ANN) (Kalogirou, 2004; Esen, 2009; Esen Brus 2010; Fischer, 2012), multiple linear regression based model (Kicsiny, 2014). These models usually characterize the collector thermal behaviors without clear recognition of physical meanings or the model coefficients do not have definite physical meanings. In this sense, the model can not be used to identify the collector characteristic parameters in dynamic tests. Thus, they are also called as the black-box models (Esen Brus 2010; Kicsiny, 2014). They usually can not be explained from physical essence, except validation on the basis of practical conditions. 
The applicability of the black-box models may be restricted to some extent because the fitting of the model coefficients is strongly dependent on the test data samples and different test data samples may give rise to different model coefficients.

Figure 1 (a) Single glass flat-plate solar collector with parallel riser pipes taking water/antifreeze fluid as the working fluid; (b) Single pass flat-plate solar air collector with straight fins and single transparent cover.

When it comes to the physical models of solar collectors, they are usually derived from analytical derivation and have model coefficients of definite physical meanings. In this sense, they are also called white-box models (Kicsiny, 2014). A series of collector dynamic/transient models of this kind were aimed at obtaining the collector characteristic parameters in order to extend the test conditions to broad meteorological conditions rather than restrict limitations required by the steady-state test (Perers, 1993, 1997; Amer et al., 1997,1999; Nayak, 2000; Fischer et al., 2004; Deng et al., 2015a, b). The QDT (Quasi-Dynamic Test) model (Perers, 1993, 1997) was a typical semi-empirical model which considered different types of effects of the collector heat losses. Although there were some other multi-node models and filtering models (Amer et al., 1997,1999; Nayak, 2000), most of them were not convenient for practical application. Hence, the majority studies focused on the applicability of the QDT and its extended model. Kong et al. (2015) proposed a new Laplace method based QDT model for solar collector dynamic tests using the nonlinear regression to 
get the collector characteristic parameters by following regulated principles of sample data selection. But the model they used was not convenient for prediction of collector performance due to highly nonlinear mathematical model.

Deng et al. (2015c) presented an analytical model revealing that the instantaneous useful heat gain of a solar collector at one moment consists of the steady-state useful heat gain and corresponding thermal inertia correction. Amrizal et al. (2012) put forward a simple dynamic model for thermal characterization of solar collectors based on the piston flow concept by approximation of the dynamic solar collector model presented by Muschaweck and Spirkl (1993). The schematic illustration of the fluid movement through the collector in the concept of piston flow was shown in Figure 2 (Amrizal et al. 2012). In the simple dynamic model, they set the model coefficient $c_{3}$ $=1$ considering the thermal capacitance of the working fluid $\left(\dot{m}_{f} c_{f}\right)$ much greater than the heat loss of the collector segment $\left(F^{\prime} U_{L} A_{\text {seg }}\right)$. But it might not be the case for some specific flat-plate solar collectors, which will be discussed later in the present study. In addition, Amrizal et al. (2012) defined the heat transport time $\tau_{t}=\left(1-e^{-1}\right)^{-1} \tau_{C}$ without logical derivation, which should be defined by analysis. Moreover, in our recent study (Deng et al., 2016a), it was found that the collector effective thermal capacitance in the QDT should be amended using two-node lumped heat capacitance method according to the definition of the collector flow efficiency factor. It should be considered in the simple model in order to determine the collector characteristic parameters. 
Figure 2 A schematic illustration of the fluid movement through the collector according to the piston flow concept (Amrizal et al. 2012)

In the present study, the simple collector dynamic characterization model presented by Amrizal et al. (2012) was investigated both to determine the characteristic parameters and to predict the thermal performance of flat-plate solar collectors under dynamic meteorological conditions. The primary aim of the present study was to validate the accuracy of the simple collector model by Amrizal et al. (2012). The model was validated with a single pass flat-plate solar air collector tested previously in Deng et al. (2016a). The heat transport time defined in the original model was corrected through deduction. Moreover, the simple dynamic model based on the first-order difference method was compared to the numerical solution of the collector ODE model by the fourth-order Runge-Kutta method as well as the improved thermal inertia model (TIM) based on the closed-form integral solution presented in our recent published work (Deng et al., 2016a).

\section{Model used}

2.1 The simple dynamic model based on piston flow concept (Amrizal et al., 2012)

The simple collector dynamic model was constructed by Amrizal et al. (2012) considering the first-order difference of the time and spatial segments for the ordinary 
differential equation (1), which is an approximation of the quick dynamic test model of solar collectors (Muschaweck and Spirkl, 1993). In the model the solar collector was evenly divided into $N$ segments as shown in Figure 2 and each segment should fulfil Equation (1).

$$
(m c)_{s e g} \frac{d T}{d \tau}=A_{s e g}\left[F^{\prime}(\tau \alpha)_{e n} K_{\theta}(\theta) G_{g}-F^{\prime} U_{L}\left(T-T_{a}\right)\right]-\dot{m}_{f} c_{f}\left(T-T_{0}\right)
$$

where $(m c)_{\text {seg }}$ denotes the effective thermal capacity of the segment; $T$ is the uniform fluid temperature of the segment and $T_{0}$ is the fluid temperature at the entrance of the segment; $A_{\text {seg }}$ is the segment area; $F^{\prime}(\tau \alpha)_{e n}$ represents the optical efficiency of the collector consisting of the collector flow efficiency $F^{\prime}$ and the effective transmittance-absorptance product $(\tau \alpha)_{e n}$ (ANSI/ASHRAE Standard 93-2003, 2003); $K_{\theta}(\theta)$ indicates the incidence angle modifier; $G_{g}$ is the global solar irradiance on the collector surface; $U_{L}$ is the total collector heat loss coefficient; $T_{a}$ is the ambient temperature; $\dot{m}_{f}$ is the mass flow rate of the working fluid; $c_{f}$ is the specific heat capacity of the working fluid.

Substituting the derivative term $d T / d \tau$ in Equation (1) using first-order finite difference, Equation (2) is obtained. Equation (2) can be further simplified as Equation (4) by constructing the relationship in Equation (3) considering that the thermal capacitance of the collector segment $\left((m c)_{\text {seg }}\right)$ equals that of the working fluid removed in the time interval $\Delta \tau$. Then an algebraic recursive relation is obtained by rearranging Equation (4), as shown in Equation (5). 


$$
(m c)_{s e g} \frac{T_{i x}^{i t}-T_{i x}^{i t-1}}{\Delta \tau}=A_{s e g}\left[F^{\prime}(\tau \alpha)_{e n} K_{\theta}(\theta) G_{g}^{i t}-F^{\prime} U_{L}\left(T_{i x}^{i t}-T_{a}^{i t}\right)\right]-\dot{m}_{f} c_{f}\left(T_{i x}^{i t-1}-T_{i x-1}^{i t-1}\right)
$$

where $T_{i x}^{i t}$ is the fluid temperature at the ' $i x$-th' segment and the 'it-th' time step; $\Delta \tau$ is the time interval; $T_{i x}^{i t-1}$ is the fluid temperature at the ' $i x$-th' segment and the '(it-1)-th' time step; $\Delta \tau$ is the time interval.

$$
\begin{aligned}
& \frac{(m c)_{s e g}}{\Delta \tau}=\dot{m}_{f} c_{f} \\
& \dot{m}_{f} c_{f}\left(T_{i x}^{i t}-T_{i x-1}^{i t-1}\right)=A_{s e g}\left[F^{\prime}(\tau \alpha)_{e n} K_{\theta}(\theta) G_{g}^{i t}-F^{\prime} U_{L}\left(T_{i x}^{i t}-T_{a}^{i t}\right)\right] \\
& T_{i x}^{i t}=\frac{A_{s e g} F^{\prime}(\tau \alpha)_{e n} K_{\theta}(\theta) G_{g}^{i t}+A_{s e g} F^{\prime} U_{L} T_{a}^{i t}+\dot{m}_{f} c_{f} T_{i x-1}^{i t-1}}{\dot{m}_{f} c_{f}+F^{\prime} U_{L} A_{s e g}}
\end{aligned}
$$

Equation (5) can be compacted as Equation (6) using three model coefficients $c_{1}-c_{3}$. Equation (6) is just the simple collector dynamic model using the first-order backward difference $\left(T_{i x}^{i t}-T_{i x}^{i t-1}\right) / \Delta \tau$ instead of the derivative term $d T / d \tau$ and fulfilling Equation (3) for segment division. It indicates that the collector fluid temperature $T_{i x}^{i t}$ at the 'it-th' time step and ' $i x$-th' spatial step depends upon the global solar irradiance $G_{g}$, ambient temperature $T_{a}$ at the current time step as well as the fluid temperature at the previous the '(it-1)-th' time step and '(ix-1)-th' spatial step. As shown in Equation (7), it is essentially a recursive relationship which reveals that the collector fluid temperature $T_{i x}^{i t}$ at the specific time is related to the effect of the global solar irradiance $G_{g}$ and ambient temperature $T_{a}$ over a period of time before the current time step. Moreover, the effect of global solar irradiances $c_{3}^{0} G_{g}^{i t}, c_{3}^{1} G_{g}^{i t-1}, c_{3}^{2} G_{g}^{i t-2}$, $\ldots c_{3}^{N} G_{g}^{i t-N}$ at the previous time steps successively weaken as the time step decreases 
from ' 0 ' to ' $N$ ' because the coefficient $c_{3}$ is less than 1 . The same effect appears to the ambient temperature. Presumably, when the previous time step '(it-n)-th' is sufficiently long away from the current time step 'it-th', the effect factor $c_{3}^{n}$ (corresponding exponent index $n$ is big enough) in Equation (7) is very small and the effect of global solar irradiance and ambient temperature on the collector fluid temperature of ' $i x$-th' segment before the time step '(it-n)-th' can be neglected due to the attenuation of the effect. The mechanism of the thermal lag effects of solar radiation and ambient temperature is due to thermal inertia effect of the collector mass, which is already elucidated in our previous work (Deng et al., 2015c). In this sense, it is not wise to directly set the coefficient $c_{3}=1$ as argued by Amrizal et al. (2012), which will be discussed in section 4.3.

$$
T_{i x}^{i t}=c_{1} G_{g}^{i t}+c_{2} T_{a}^{i t}+c_{3} T_{i x-1}^{i t-1}
$$

where $c_{1}=\frac{A_{\text {seg }} F^{\prime}(\tau \alpha)_{e n} K_{\theta}(\theta)}{\dot{m}_{f} c_{f}+F^{\prime} U_{L} A_{\text {seg }}}, c_{2}=\frac{F^{\prime} U_{L} A_{\text {seg }}}{\dot{m}_{f} c_{f}+F^{\prime} U_{L} A_{\text {seg }}}$ and $c_{3}=1-c_{2}$

$$
\begin{aligned}
T_{i x}^{i t}= & c_{1} G_{g}^{i t}+c_{2} T_{a}^{i t}+c_{3}\left(c_{1} G_{g}^{i t-1}+c_{2} T_{a}^{i t-1}+c_{3} T_{i x-2}^{i t-2}\right) \\
= & c_{1}\left(G_{g}^{i t}+c_{3} G_{g}^{i t-1}\right)+c_{2}\left(T_{a}^{i t}+c_{3} T_{a}^{i t-1}\right)+c_{3}^{2} T_{i x-2}^{i t-2} \\
= & c_{1}\left(G_{g}^{i t}+c_{3} G_{g}^{i t-1}+c_{3}^{2} G_{g}^{i t-2}\right)+c_{2}\left(T_{a}^{i t}+c_{3} T_{a}^{i t-1}+c_{3}^{2} T_{a}^{i t-2}\right)+c_{3}^{3} T_{i x-3}^{i t-3} \\
= & c_{1}\left(G_{g}^{i t}+c_{3} G_{g}^{i t-1}+c_{3}^{2} G_{g}^{i t-2}+\ldots c_{3}^{n} G_{g}^{i t-n}\right) \\
& \quad+c_{2}\left(T_{a}^{i t}+c_{3} T_{a}^{i t-1}+c_{3}^{2} T_{a}^{i t-2}+\ldots c_{3}^{n} T_{a}^{i t-n}\right)+c_{3}^{n+1} T_{i x-n-1}^{i t-n-1}
\end{aligned}
$$

where it, ix $\geq 3$, it $>n$.

Noting that $T_{N}^{i t}$ is the data sequence of the collector outlet temperature $\left(T_{f o}^{i t}\right)$ and $T_{0}^{i t}$ 
denotes the collector inlet temperature $\left(T_{f i}^{i t}\right)$ according to the collector segment division illustrated in Figure 2, the collector outlet temperature $T_{N}^{i t}$ can be expressed as Equation (8) using Equation (6) or (7). Equation (8) is different from the multilinear relationship described by Amrizal et al. (2012) since $c_{3}$ can not be hastily set as 1 .

$$
T_{f o}^{i t}=c_{1} \sum_{j=1}^{N} c_{3}^{j-1} G_{g}^{i t-j+1}+c_{2} \sum_{j=1}^{N} c_{3}^{j-1} T_{a}^{i t-j+1}+c_{3}^{N} T_{f i}^{i t-N}
$$

In order to determine the collector segment number $N$, the heat transport time $\tau_{t}$ in Equation (9) was defined as the time needed for the flowing fluid to remove the heat stored by the solar collector (Amrizal et al., 2012). The authors gave the calculation method of $\tau_{t}$ by Equation (10), which was not extracted by logical derivation and would be identified in section 2.3. The collector segment number $N$ is calculated by Equation (11), which means that the time interval $\Delta \tau$ is the heat transport time of the working fluid in a single segment.

$$
\begin{aligned}
\tau_{t} & =\frac{(m c)_{e}}{\dot{m}_{f} c_{f}} \\
\tau_{t} & =\left(1-e^{-1}\right)^{-1} \tau_{C} \\
N & =\frac{\tau_{t}}{\Delta \tau}
\end{aligned}
$$

\subsection{The ODE model for flat plate solar collectors}

Deng et al. (2016a) presented the two-node lumped heat capacitance model of the 
flat-plate solar collectors based on the definition of the collector flow efficiency factor $F^{\prime}$, as shown in Equation (12) which substituted $F^{\prime}(M c)_{e}$ instead of $(M c)_{e}$ as the effective collector thermal capacitance. And the authors put forward the improved TIM for the lumped variable model. The improved TIM is just the closed-form integral solution of Equation (12). While the simple dynamic model by Equation (6) or (8) is essentially the first-order finite difference solution of the collector ODE model in Equation (12). In order to get a higher order numerical solultion of the ODE for comparison, the numerical ODE model is presented and solved by the fourth-order Runge-Kutta method. Taking the arithmetic mean temperature of the working fluid as the whole collector fluid characteristic temperature, $T=\left(T_{f i}+T_{f o}\right) / 2$, Equation (12) is changed to Equation (13).

$$
\begin{gathered}
F^{\prime}(M c)_{e} \frac{d T}{d \tau}=A_{a}\left[F^{\prime}(\tau \alpha)_{e n} K_{\theta}(\theta) G_{g}-F^{\prime} U_{L}\left(T-T_{a}\right)\right]-\dot{m}_{f} c_{f}\left(T_{f o}-T_{f i}\right) \\
F^{\prime}(M c)_{e} \frac{d\left(\left(T_{f i}+T_{f o}\right) / 2\right)}{d \tau}=A_{a}\left[F^{\prime}(\tau \alpha)_{e n} K_{\theta}(\theta) G_{g}-F^{\prime} U_{L}\left(\left(T_{f i}+T_{f o}\right) / 2-T_{a}\right)\right] \\
-\dot{m}_{f} c_{f}\left(T_{f o}-T_{f i}\right)
\end{gathered}
$$

Generally, the collector inlet temperature $T_{f i}$ for the whole collector is a known quantity and $T_{f i}$ in the derivative term on the right can be reduced. Thus, Equation (14) is obtained.

$$
\frac{F^{\prime}(M c)_{e}}{2 \dot{m}_{f} c_{f}} \frac{d T_{f o}}{d \tau}=\frac{A_{a} F^{\prime}(\tau \alpha)_{e n} K_{\theta}(\theta)}{\dot{m}_{f} c_{f}} G_{g}-\frac{A_{a} F^{\prime} U_{L}}{\dot{m}_{f} c_{f}}\left(\left(T_{f i}+T_{f o}\right) / 2-T_{a}\right)-\left(T_{f o}-T_{f i}\right)
$$

Considering the collector outlet temperature $T_{f o}$ as the unknown parameter, the 
above equation can be rearranged as Equation (15).

$$
C \cdot \frac{d T_{f o}}{d \tau}=A \cdot T_{f o}+b
$$

where $C=\frac{F^{\prime}(M c)_{e}}{2 \dot{m}_{f} c_{f}}, A=-\left(1+\frac{A_{a} F^{\prime} U_{L}}{2 \dot{m}_{f} c_{f}}\right)$,

$$
b=\frac{A_{a} F^{\prime}(\tau \alpha)_{e n} K_{\theta}(\theta)}{\dot{m}_{f} c_{f}} G_{g}+\frac{A_{a} F^{\prime} U_{L}}{\dot{m}_{f} c_{f}} T_{a}+\left(1-\frac{A_{a} F^{\prime} U_{L}}{2 \dot{m}_{f} c_{f}}\right) T_{f i}
$$

Equation (15) is the collector ODE model employed for the numerical solution of the fourth-order Runge-Kutta method.

\subsection{The heat transport time defined in the simple dynamic model}

It is noted in the previous section that $C=\tau_{C}$ in Equation (15) according to the definition of the collector static response time constant $\tau_{C}$ (Deng et al., 2016a; ANSI/ASHRAE Standard 93-2003, 2003). Reviewing the derivation process of the simple dynamic model, the heat transport time $\tau_{t}$ is just the collector time constant $\tau_{C}$ in Equation (16), rather than $\left(1-e^{-1}\right)^{-1} \tau_{C}$ in Equation (10) argued by Amrizal et al. (2012). Accurately determining the effective heat transport time is of significance because it indicates the effect time period of global solar irradiance and ambient temperature on the collector outlet temperature of the current time step at a specific segment, as described by Equation (8). Then the collector segment number $N$ is calculated by Equation (17). 


$$
\begin{aligned}
\tau_{t} & =\frac{F^{\prime}(m c)_{e}}{2 \dot{m}_{f} c_{f}}=\tau_{C} \\
N & =\frac{\tau_{C}}{\Delta \tau}
\end{aligned}
$$

\section{Experimental data for validation}

Steady-state tests and the dynamic tests of a typical flat-plate solar air collector with straight fins attached at the back of the absorber plate were carried out to validate the performance of the simple dynamic thermal performance characterization model. The tests were already reported in our recent work (Deng et al., 2016a). Figure 3 shows a schematic illustration of the flat-plate solar air collector used in the test. The size of the collector module was $1.995 \mathrm{~m}$ by $0.995 \mathrm{~m}$ (length by width), corresponding to a gross collector area of $1.985 \mathrm{~m}^{2}$. The collector aperture area was $1.84 \mathrm{~m}^{2}$. Structure of the flat-plate solar air collector module was consist of $3.2 \mathrm{~mm}$ tempered gyrosigma transparent glass cover (with a normal incident transmittance of 0.92 ), $0.6 \mathrm{~mm}$ absorber plate $(0.4 \mathrm{~mm}$ aluminum alloy sheet and $0.2 \mathrm{~mm}$ selective coating surface with an absorptance of 0.92 and reflectance of 0.05 ), air flow channel of $50 \mathrm{~mm}$ height and $25 \mathrm{~mm}$ fin pitch with straight fins, polyurethane foam insulation material of $50 \mathrm{~mm}$ thickness at the back of the collector and steel frame for outer package. The height of the closed air layer between the transparent glass cover and the absorber plate was $10 \mathrm{~mm}$. The installed angle of the collector was $45^{\circ}$. For more information about the test, such as the test facilities and instrumental accuracies, please refer to Deng et al. (2016a). 
Figure 3 A schematic illustration of the flat-plate solar air collector used in the test

Dynamic test data of September 19th, 2015 was chosen in further discussion because it contained inlet temperatures at different levels, which were necessary for identifying the effective collector thermal capacity (Deng et al., 2015a, 2016a; Kong et al., 2015). The day was a clear sky. Figure 4 shows measured solar irradiances and temperatures on September 19th, 2015. The time interval of the test was $10 \mathrm{~s}$. The volume airflow rate through the collector was controlled to be $100 \pm 1.5\left(\mathrm{~m}^{3} / \mathrm{h}\right)$. The initial values of the collector outlet temperature showed a sudden increase due to the open-air basking condition and the start of the draught fan, followed by a decrease due to cooling down of the collector by incoming air. Furthermore, the collector was instantaneously adjusted to be near normal incidence by adjusting the rotating rack of the test rig for the sake of testing the steady-state collector thermal efficiency curve. The collector steady-state response time constant $\tau_{C}$ was also measured through suddenly shadowing the collector surface from the time the collector arrived at a steady-state point. It can be seen from Figure 4 that the solar irradiance between 09:27 and 10:28 was zero and the collector outlet temperature gradually went down during the period. During the test the outdoor wind velocity was measured to be in the ranged of $0-2.0 \mathrm{~m} / \mathrm{s}$.

Figure 4 Measured meteorological conditions and temperatures on Sep. 19th, 2015 (Deng et al., 2016a). 


\section{Results and discussion}

\subsection{Identification of collector characteristic parameters}

Equation (8) which correlates the collector outlet temperature $T_{f o}^{i t}$ with the collector inlet temperature $T_{f i}^{i t-N}$, solar irradiance $G_{g}^{i t-j+1}$ and ambient temperature $T_{a}^{i t-j+1}$ at different time steps within the timespan of $\left[i t \cdot \Delta \tau-\tau_{C}, i t \cdot \Delta \tau\right]$ can be used for obtaining the collector characteristic parameters $F^{\prime}(M c)_{e}, F^{\prime}(\tau \alpha)_{e n}, F^{\prime} U_{L}$ by the nonlinear squares fitting method. The optimization function shown in Equation (18) is chosen as the minimum summation of differences between the predicted and the measured outlet temperatures. The collector inlet temperature, the outlet temperature, the ambient temperature and the solar irradiance are measured quantities in the collector dynamic tests. Then the collector characteristic parameters which constitute the model coefficients $c_{1}-c_{3}$ (see Equation (6)) can be determined by the nonlinear squares fitting solver - 'Isqnonlin' function in Matlab.

$$
\begin{aligned}
& \min _{x}\left\|f\left(G_{g}, T\right)\right\|_{2}^{2}=\min _{x}\left(\sum_{i t=N+1}^{M} f_{i t}^{2}\left(G_{g}, T\right)\right) \\
& f_{i t}\left(G_{g}, T\right)=c_{1} \sum_{j=1}^{N} c_{3}^{j-1} G_{g}^{i t-j+1}+c_{2} \sum_{j=1}^{N} c_{3}^{j-1} T_{a}^{i t-j+1}+c_{3}^{N} T_{f i}^{i t-N}-T_{f o}^{i t}
\end{aligned}
$$

where $M$ is the time interval number of the dynamic test data sequence and the time step before $N$ should be excluded since the collector inlet temperature during that period might be unknown. 
The collector characteristic parameters are obtained and listed in Table 1 for the flat-plate solar air collector. Table 2 gives the collector characteristic parameters obtained by the steady-state test in Deng et al. (2016a) (The calculation of $F^{\prime}(\tau \alpha)_{e n}$ through $F_{R}(\tau \alpha)_{e n}$ in the steady-state test can be found in Deng et al. (2016b). Since the collector was adjusted to be perpendicularly solar incident during the test day, the incidence angle modifier was 1 and $K_{\theta}(\theta)$ in the coefficient $c_{1}$ was eliminated. Comparing Tables 1 and 2, the collector characteristic parameters got by the simple dynamic model are nearly the same as those by the steady-state test method. The relative errors between the two methods are within $2 \%$. It indicates that the simple dynamic model is effective to get the collector characteristic parameters using the nonlinear squares fitting.

Table 1 Collector characteristic parameters obtained by the nonlinear squares fitting in Equation (8)

Table 2 Collector characteristic parameters determined by the steady-state test (Deng et al., 2016a)

\subsection{Validation of the simple dynamic model for collector thermal performance prediction with different transport times}

The model coefficients obtained by the nonlinear squares fitting in Table 1 were used to predict the outlet temperature of the solar collector. In order to demonstrate the 
effect of the heat transport time on the prediction accuracy, three values $\tau_{C}$, $\left(1-e^{-1}\right)^{-1} \tau_{C}, 2 \tau_{C}$ were chosen to compare the prediction results. The value $2 \tau_{C}$ was chosen as a comparison with the other two values. The initial temperatures of all the collector segments were set to be the collector inlet temperature since the temperatures before the initial time remained to be unknown. Figure 5 shows the prediction results of the collector outlet temperature with three different heat transport times. Because the predictions started with an initial collector inlet temperature, the thermal lag effect of initial conditions would gradually vanish after a period of time. It was verified by Deng et al. (2015c) that the time period of thermal lag effect should be at least $3 \tau_{C}$ considering that $\exp \left(3 \tau_{C} / \tau_{C}\right)=0.0498$ was small and could be neglected. In this sense, predictions of the collector outlet temperature during the time period of 9:18-9:49 (31 $\mathrm{min})$ did not make sense due to thermal lag effect of the initial conditions.

Figure 5 The collector outlet temperature predictions by the simple dynamic model with three different heat transport times compared to the measured values

Furthermore, the sum of squared relative errors between the measured values and the prediction values for the data sequence was taken as the indicator to examine the error of the predictions with different heat transport time parameters. The sum of squared relative errors is calculated by $\sum_{i t=N+1}^{M} f_{i t}^{2}\left(G_{g}, T\right)$ (see Equation (18)) using Equation (19). The initial $N$ data points were excluded from the error statistics because the 
collector inlet temperature during that period might be unknown when using Equation (8). The sums of squared relative errors for the heat transport times of $\tau_{C}$, $\left(1-e^{-1}\right)^{-1} \tau_{C}, 2 \tau_{C}$ are $9869,14215,22353$, respectively. It suggests that the case of $\tau_{t}=\tau_{C}$ has the smallest error compared to the experimental data. Therefore, it is proved that the heat transport time defined by Amrizal et al. (2012) as $\left(1-e^{-1}\right)^{-1} \tau_{C}$ should be corrected as the collector static response time constant $\tau_{C}$ in Equation (16). Regarding the prediction of collector dynamic thermal behavior presented by Amrizal et al. (2012), the authors reported that they got a good agreement between the prediction by the simple dynamic model and the experimental test with the inaccurate heat transport time $\tau_{t}=\left(1-e^{-1}\right)^{-1} \tau_{C}$. It is assumed that this is mainly because the size of the collector used by them is small (collector gross area $0.146 \mathrm{~m}^{2}$ ) and the collector thermal lag effect is not evident.

\subsection{Effect of the approximation treatment of the model coefficient $c_{3}=1$}

It was reported by Amrizal et al. (2012) that the model coefficient $c_{3}$ in Equation (6) or (8) could be set as 1 since the term $\dot{m}_{f} c_{f}$ was very large compared to $F^{\prime} U_{L} A_{\text {seg }}$ for conventional flat-plate solar thermal collectors. The parameter fitting results of the studied solar collector listed in Table 1 also showed that the coefficient $c_{3}$ approximately equaled 1 . However, when $c_{3}=1$ was used for the collector outlet temperature prediction, it resulted in a strong overestimation, as shown in Figure 6. The relative errors between the predicted temperatures with $c_{3}=1$ and the measured 
temperatures ranged from $35.6 \%-72.3 \%$ during the period of 9:49 am - 14:29 pm for the studied test condition. This was mainly because the power exponent of coefficient $c_{3}$ had a strong relationship with the damping effect of the meteorological conditions such as solar irradiance and ambient temperature, which was explained in section 2.1. Therefore, the model coefficient $c_{3}$ can not be hastily set to 1 for prediction although it is usually close to 1 . Otherwise, the damping effect is inaccurately modeled probably resulting in a wrong prediction.

Figure 6 The collector outlet temperature predictions by the simple dynamic model in Equation (8) and the case of the coefficient $c_{3}=1$

\subsection{Comparisons of the simple dynamic model with the fourth-order numerical solution of the ODE model and the improved TIM}

The simple model was derived from the quick dynamic test model of solar collectors (Muschaweck and Spirkl, 1993) considering approximation of the derivative term $d T / d \tau$ in Equation (1) using the first-order finite difference method. In order to compare the difference of prediction accurancy among different solution methods of $d T / d \tau$, the higher-order numerical solution of the collector ODE model in Equation (15) was achieved by the fourth-order Runge-Kutta method. The improved TIM of the flat-plate solar collectors based on the two-node lumped heat capacitance (Deng et al., 2016a), which was the closed-form solution of the ODE model, was considered as the comparison benchmark. Figure 7 gives the comparison of the collector outlet 
temperature predictions by different solution models. It could be seen that when the global irradiance was sharply changed to zero for a long period $(10: 28-11: 26)$ the simple dynamic model was not so accurate as the fourth-order numerical ODE solution and the closed-form integral solution (TIM). The former was linear variation while the latter two turned out to be exponential attenuation. This was due to the fact that the simple dynamic model adopted the first-order finite difference method to approximately solve the derivative term $d T / d \tau$, while the fourth-order numerical ODE solution used the fourth-order Runge-Kutta method and the TIM based on the closed-form integral solution. Besides, the prediction by the simple dynamic model was somewhat delayed during the time periods of 12:18-12:28, 14:01 -14:11, etc. when the rate of change of the collector inlet temperature was intensive. It was reckoned that the error was due to the delayed thermal lag effect of the piston flow. The sums of squared relative errors between the prediction values and the measured values were also calculated for different prediction models. The relative error sums of squares for the simple dynamic model, the improved TIM and the fourth-order numerical ODE solution model were $9869,4487,8459$, respectively. It suggested that the prediction performance of the simple dynamic model was fairly well except some special conditions such as sharply changed solar irradiance and collector inlet temperature.

Additionally, it was worth mentioning that the simple model (Equation (8)) was based on the first-order differential scheme which was essentially an approximation 
treatment with the first-order truncation error. While the numerical solution using the fourth-order Runge-Kutta method had a fourth-order truncation error, in contrary to the closed-form accurate solution of the improved TIM by Deng et al. (2016a). In this sense, it was understandable that the simple model by Equation (8) performed slightly poorer than the fourth-order numerical solution and the closed-form solution (the improved TIM). Nevertheless, the simple dynamic model can help to understand the thermal inertia effect of solar collectors and it is convenient to be used in real engineering in most conditions. Besides, the fourth-order numerical solution was not as accurate as the closed-form solution as seen in Figure 7.

Figure 7 Comparisons of the collector outlet temperature predictions by different solution models with the measured data. Simple model - the simple dynamic model based on the piston flow concept; Improved TIM - The improved thermal inertia model of flat-plate solar collectors based on the two-node lumped heat capacitance (Deng et al., 2016a); ODE 45 - the prediction of the fourth-order numerical solution of Equation (15) using the ode45 solver in Matlab

\section{Conclusions}

(1) Analytical derivation and experimental validation of the simple dynamic model indicates that the heat transport time originally defined by Amrizal et al. (2012) is proved to be the collector response time constant $\tau_{C}$ instead of $\left(1-e^{-1}\right)^{-1} \tau_{C}$. Furthermore, the model coefficient $c_{3}$ can not be hastily set to 
1 although it is close to 1 , because the power exponent of coefficient $c_{3}$ has a strong relationship with the damping effect of the meteorological conditions such as solar irradiance and ambient temperature. If the coefficient $c_{3}$ is roughly set to 1 , the damping effect is inaccurately modeled probably resulting in a wrong prediction.

(2) The simple dynamic model based on the piston flow concept can be used for both the collector parameter identification and thermal performance prediction under dynamic conditions. The nonlinear least squares fitting method should be used to identify the collector characteristic parameters.

(3) The simple dynamic model is essentially the first-order finite difference solution of the ODE by dividing the collector into $N$ equal segments along the flow direction. The model is compared to the numerical solution of ODE using the fourth-order Runge-Kutta method and the improved TIM based on the closed-form integral solution. The results show that the simple dynamic model predicts fairly well as the other two solution models except some special conditions such as sharply changed solar irradiance and collector inlet temperature.

\section{Acknowledgement}

This work was supported by the Project in Chinese National Science \& Technology Pillar Program during the Twelfth Five-year Plan Period (No. 2015BAA02B4), the 
National Natural Science Foundation of China (No. 51506193 and No. 51476164), Guangdong Innovative and Entrepreneurial Research Team Program (No. 2013N070) and China Scholarship Council (CSC No. 201504910177).

\section{References}

Amer E.H., Nayak J.K., Sharma G.K., 1997. Transient test methods for flat-plate collectors: review and experimental evaluation. Solar Energy 60 (5), 229-243.

Amer E.H., Nayak J.K., Sharma G.K., 1999. A new dynamic method for testing solar flat plate collectors under variable weather. Energy Conversion and Management 40(8), 803-823.

Amrizal N., Chemisana D., Rosell J.I., et al., 2012. A dynamic model based on the piston flow concept for the thermal characterization of solar collectors. Applied Energy 94, 244-250.

ANSI/ASHRAE Standard 93-2003. Methods of Testing to Determine the Thermal Performance of Solar Collectors. Atlanta: ASHRAE Inc., 2003.

Deng, J., Yang, X.D., Wang, P.S., 2015a. Study on the second-order transfer function models for dynamic tests of flat-plate solar collectors Part I: A proposed new model and a fitting methodology. Solar Energy 114, 418-426.

Deng, J., Yang, X.D., Wang, P.S., 2015b. Study on the second-order transfer function models for dynamic tests of flat-plate solar collectors Part II: Experimental validation. Solar Energy. http://dx.doi.org/10.1016/j.solener.2015.01.045 (in 
press).

Deng, J., Xu, Y.P., Yang, X.D., 2015c. A dynamic thermal performance model for flat-plate solar collectors based on the thermal inertia correction of the steady-state test method. Renewable Energy 76, 679-686.

Deng J., Ma R.J., Yuan G.F., et al.,2016a. Dynamic thermal performance prediction model for the flat-plate solar collectors based on the two-node lumped heat capacitance method. Solar Energy 135, 769-779.

Deng J., Yang X.D., Ma R.J., et al. 2016b. Study on the thermodynamic characteristic matching property and limit design principle of general flat plate solar air collectors (FPSACs). Building Simulation 9(5), 529-540.

Esen H., Ozgen F., Esen M., et al., 2009. Artificial neural network and wavelet neural network approaches for modelling of a solar air heater. Expert systems with applications 36(8), 11240-11248.

Esen Brus L., Zambrano D., 2010. Black-box identification of solar collector dynamics with variant time delay. Control Engineering Practice 18(10), 11331146.

Fischer S., Heidemann W., Müller-Steinhagen H., et al. 2004. Collector test method under quasi-dynamic conditions according to the European Standard EN12975-2. Solar Energy 76 (1), 117-123.

Fischer S., Frey P., Druck H., 2012. A comparison between state-of-the-art and neural network modelling of solar collectors. Solar Energy 86 (11), 3268-3277.

Kalogirou S.A., 2004. Optimisation of solar systems using artificial neural networks 
and genetic algorithms. Applied Energy 77(4), 383-405.

Kicsiny R., 2014. Multiple linear regression based model for solar collectors. Solar Energy 110 (5), 496-506.

Kong, W.Q., Perers, B., Fan, J.H., Furbo, S., Bava, F., 2015. A new Laplace transformation method for dynamic testing of solar collectors. Renewable Energy $75,448-458$.

Muschaweck J., Spirk1 W., 1993. Dynamic solar collector performance testing. Solar Energy Material and Solar Cells 30, 95-105.

Nayak J.K., Amer E.H., Deshpande S.M., 2000. Comparison of three transient methods for testing solar flat-plate collectors. Energy Conversion and Management 41(7), 677-700.

Perers B., 1993. Dynamic method for solar collector array testing and evaluation with standard database and simulation programs. Solar Energy 50(6), 517-526.

Perers B., 1997. An improved dynamic solar collector test method for determination of non-linear optical and thermal characteristics with multiple regression. Solar Energy 59(4-6), 163-178. 


\section{Figure Captions:}

Figure 1 (a) Single glass flat-plate solar collector with parallel riser pipes taking water/antifreeze fluid as working fluid; (b) Single pass flat-plate solar air collector with straight fins and single transparent cover.

Figure 2 A schematic illustration of the fluid movement through the collector according to the piston flow concept (Amrizal et al., 2012)

Figure 3 A schematic illustration of the flat-plate solar air collector used in the test

Figure 4 Measured meteorological conditions and temperatures on Sep. 19th, 2015 (Deng et al., 2016a).

Figure 5 The collector outlet temperature predictions by the simple dynamic model with three different heat transport times compared to the measured values

Figure 6 The collector outlet temperature predictions by the simple dynamic model in Equation (8) and the case of the coefficient $c_{3}=1$

Figure 7 Comparisons of the collector outlet temperature predictions by different solution models with the measured data. Simple model - the simple dynamic model based on the piston flow concept; Improved TIM - The improved thermal inertia model of flat plate solar collectors based on the two-node lumped heat capacitance (Deng et al., 2016a); ODE 45 - the prediction of the fourth-order numerical solution of Equation (15) using the ode45 solver in Matlab 


\section{Figures:}
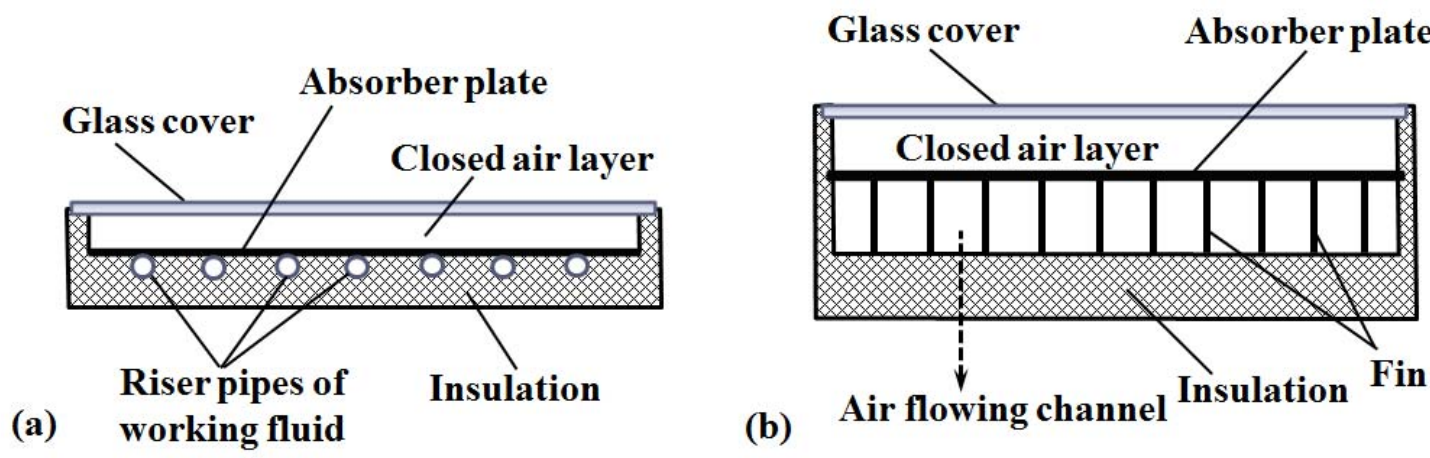

Figure 1 (a) Single glass flat-plate solar collector with parallel riser pipes taking water/antifreeze fluid as working fluid; (b) Single pass flat-plate solar air collector with straight fins and single transparent cover. 


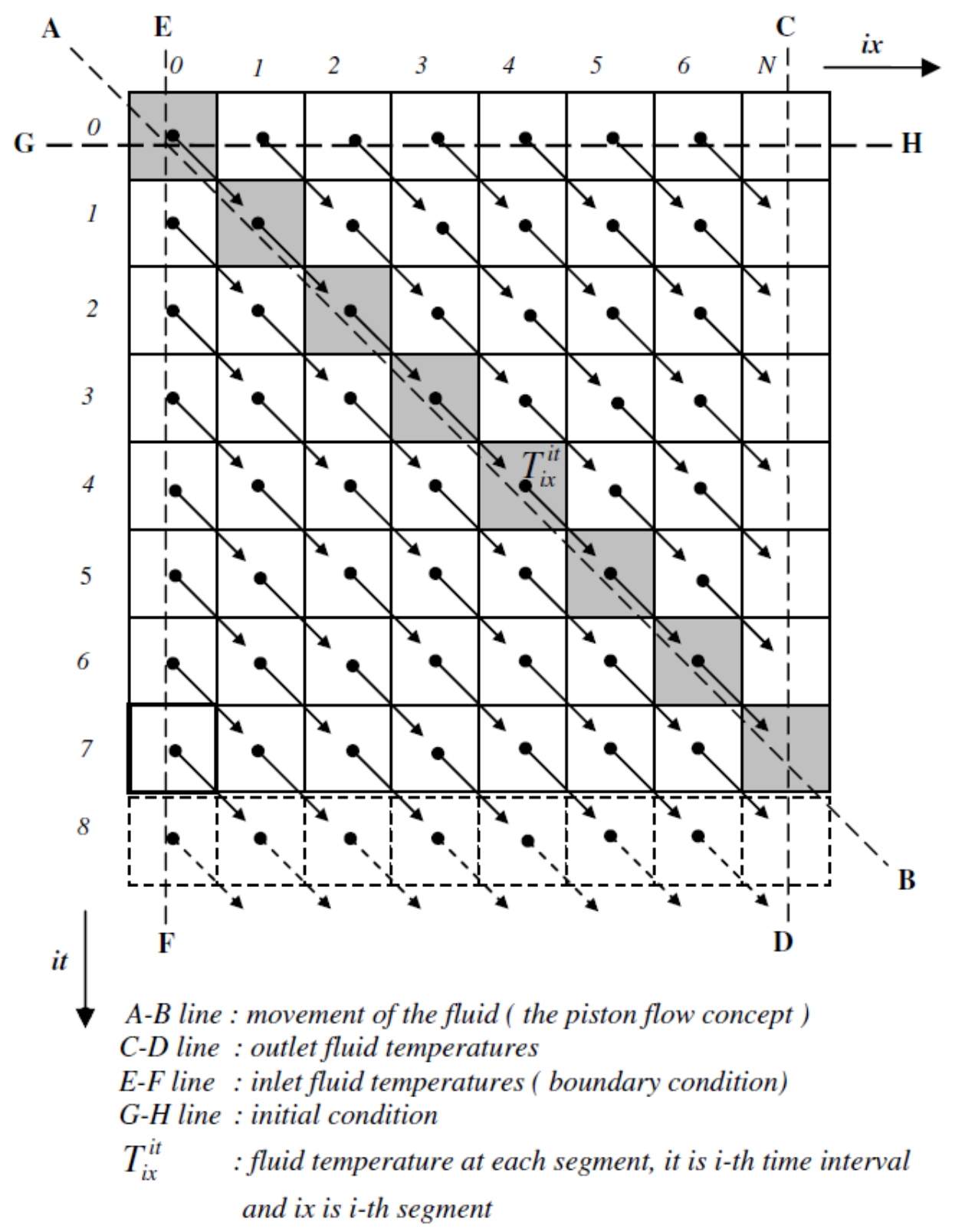

Figure 2 A schematic illustration of the fluid movement through the collector according to the piston flow concept (Amrizal et al., 2012) 

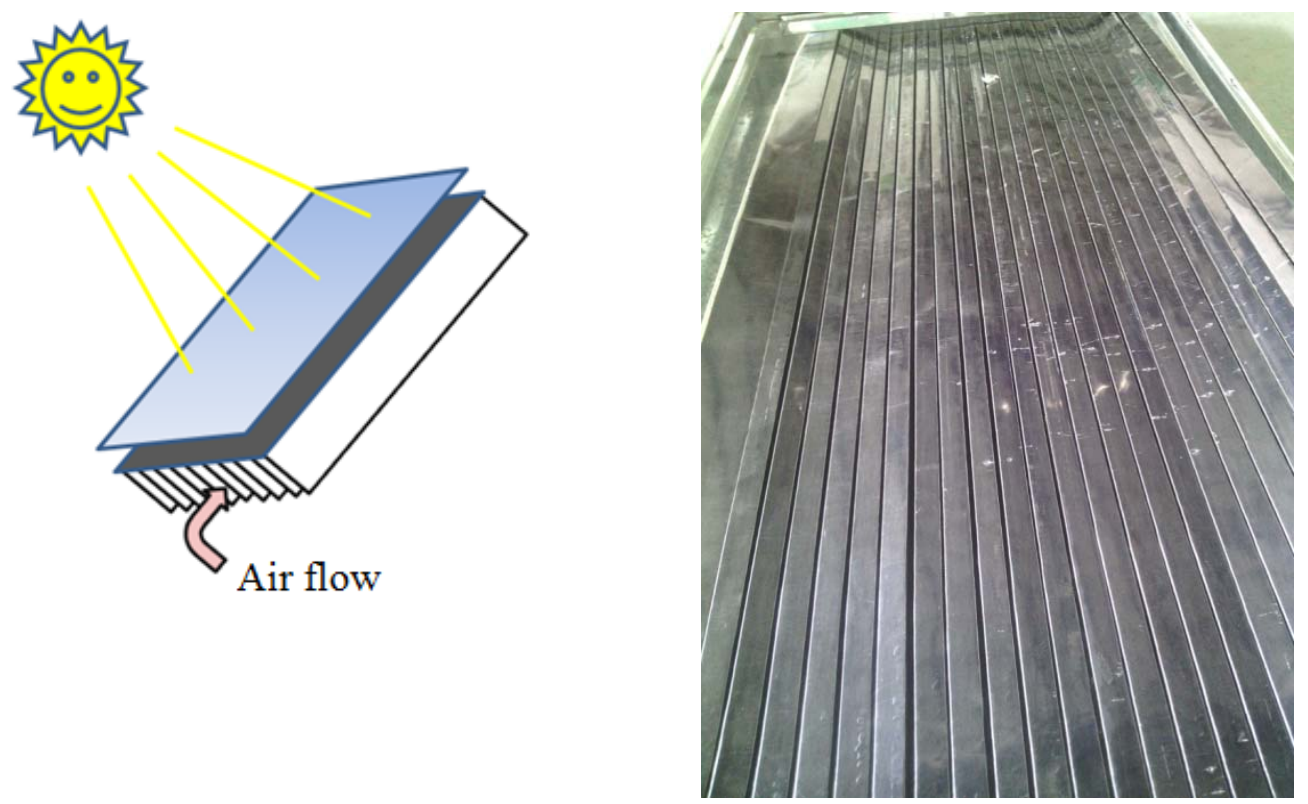

(a) Schematic of the solar air collector

(b) The absorber plate
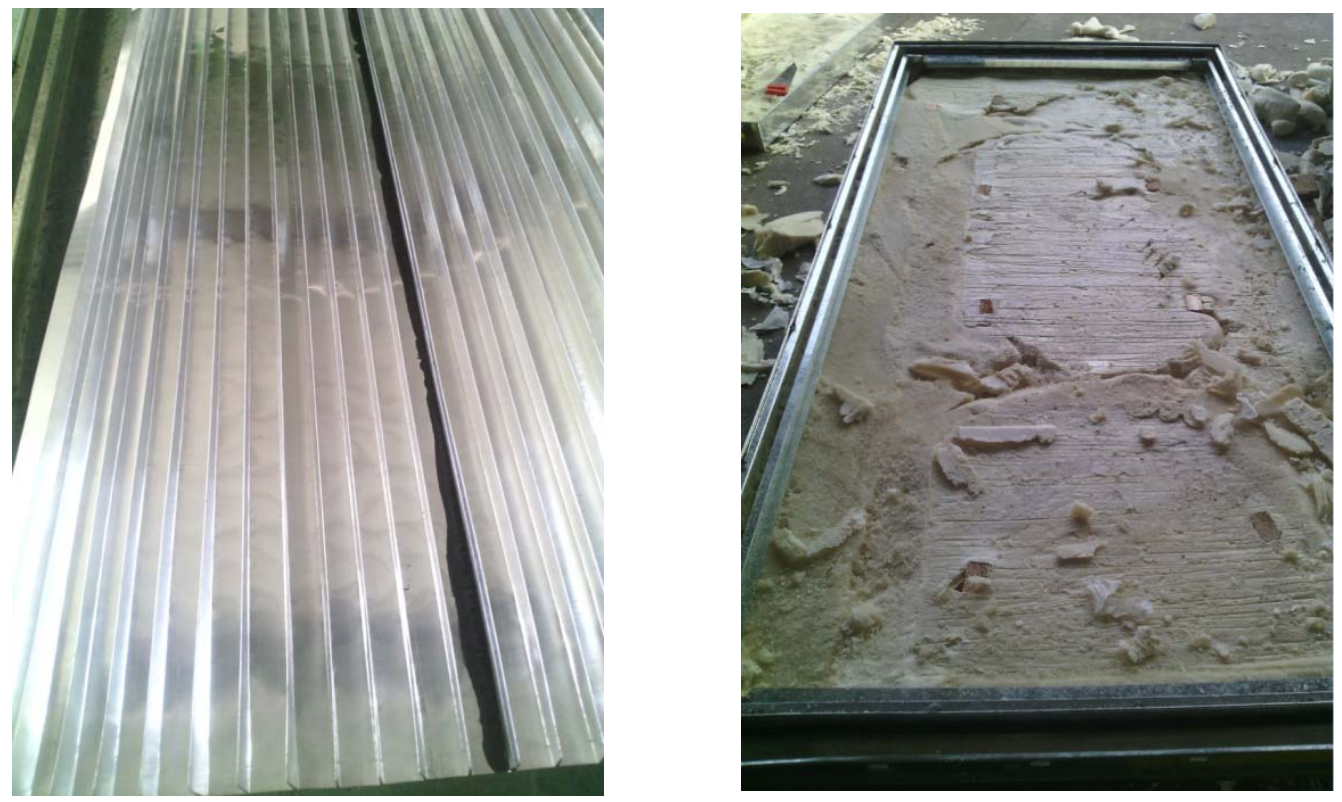

(c) The straight fins at the back of the absorber plate directly made by folding

(d) Thermal insulation at the back

Figure 3 A schematic illustration of the flat-plate solar air collector used in the test 


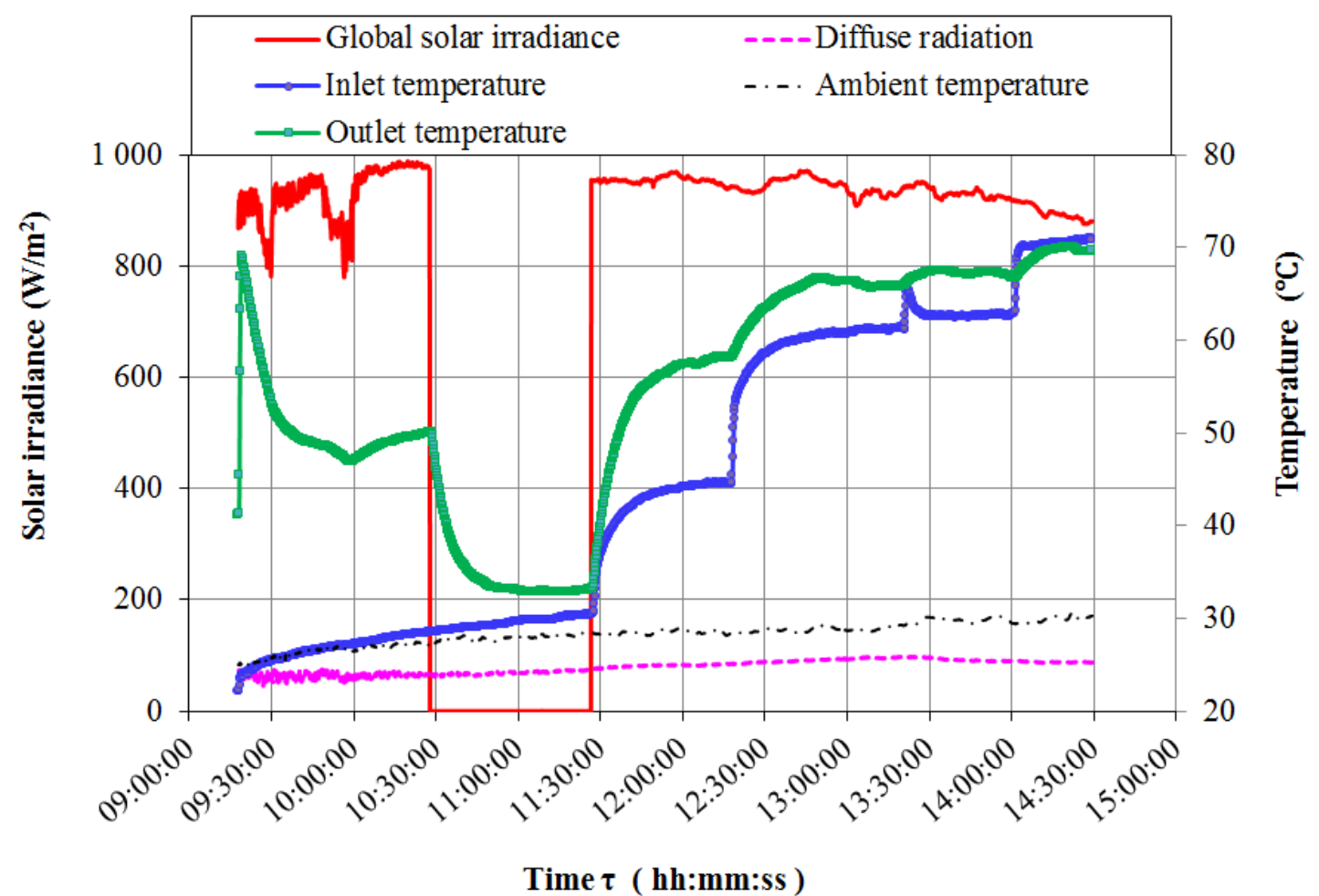

Figure 4 Measured meteorological conditions and temperatures on Sep. 19th, 2015

(Deng et al., 2016a). 


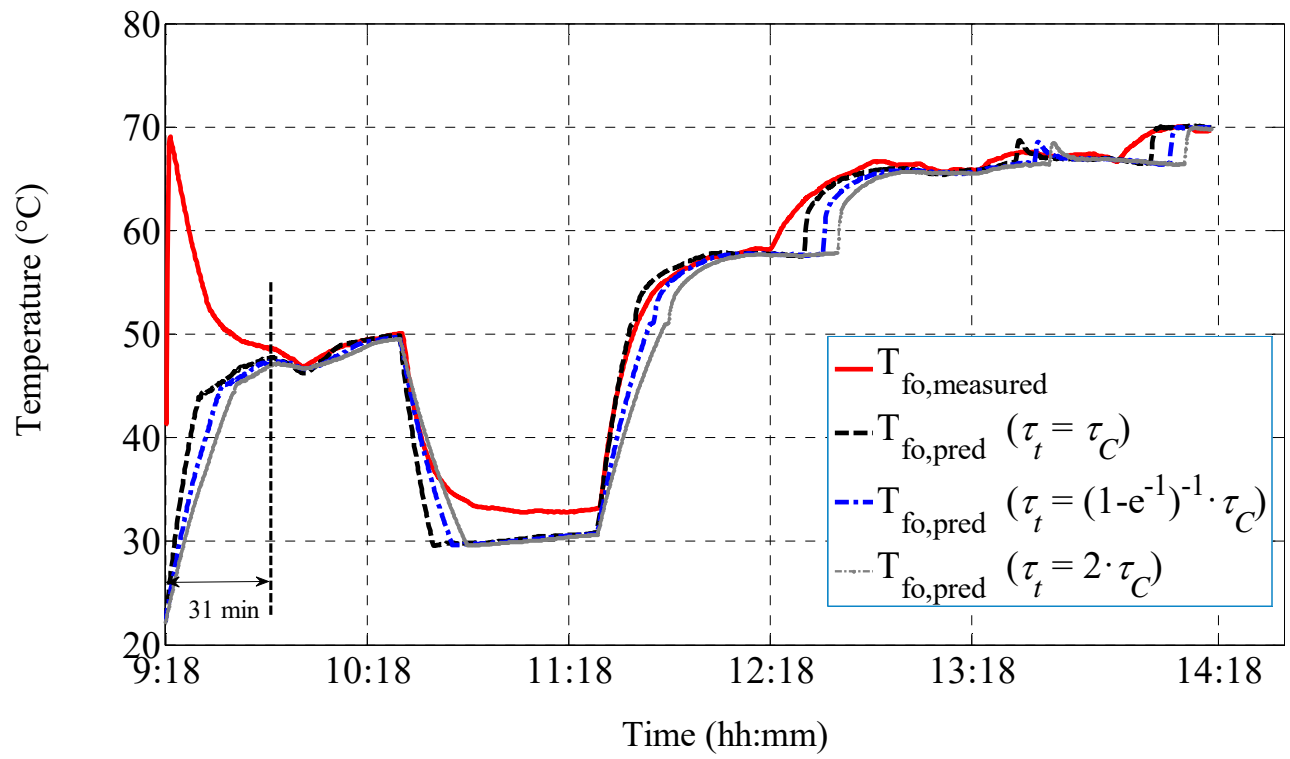

Figure 5 The collector outlet temperature predictions by the simple dynamic model with three different heat transport times compared to the measured values 


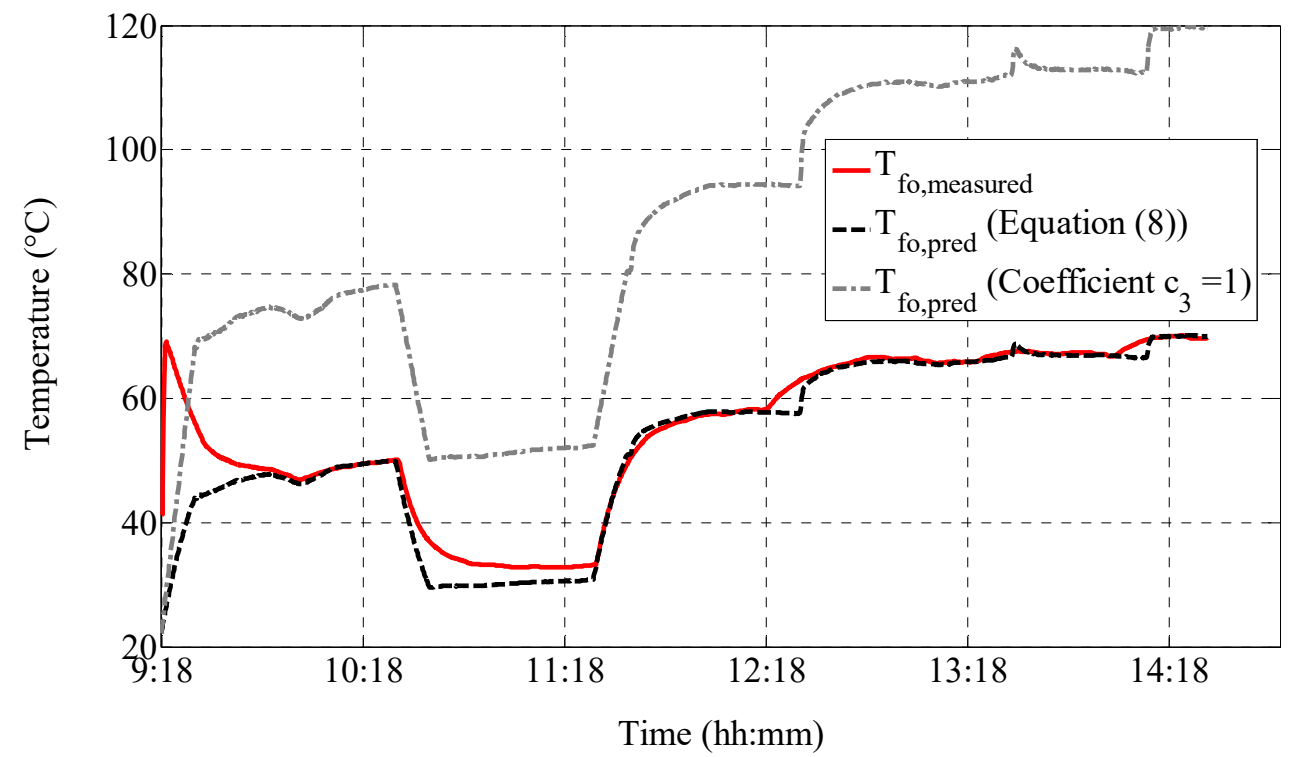

Figure 6 The collector outlet temperature predictions by the simple dynamic model in Equation (8) and the case of the coefficient $c_{3}=1$ 


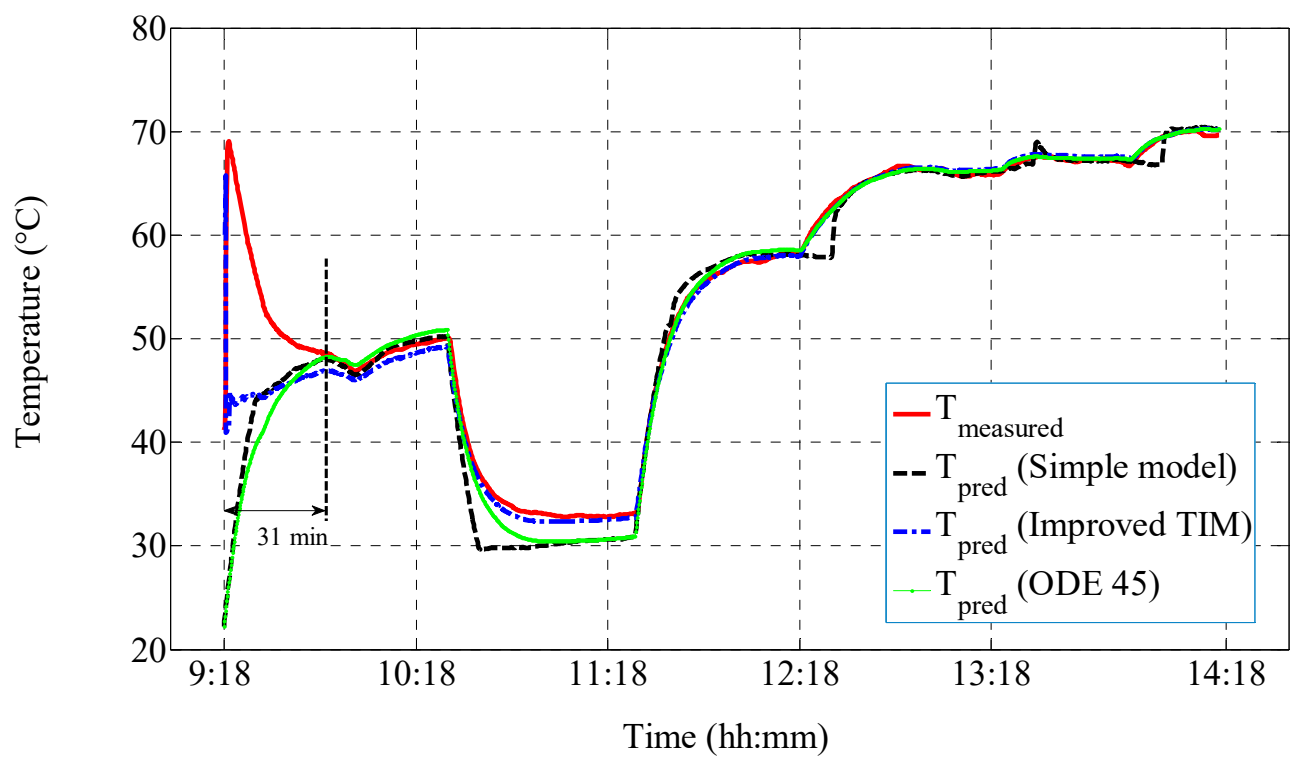

Figure 7 Comparisons of the collector outlet temperature predictions by different solution models with the measured data. Simple model - the simple dynamic model based on the piston flow concept; Improved TIM - The improved thermal inertia model of flat-plate solar collectors based on the two-node lumped heat capacitance (Deng et al., 2016a); ODE 45 - the prediction of the fourth-order numerical solution of Equation (15) using the ode45 solver in Matlab 


\section{Tables:}

Table 1 Collector characteristic parameters obtained by the nonlinear squares fitting in Equation (8)

\begin{tabular}{ccccccc}
\hline $\begin{array}{c}A_{a} / A_{g} \\
{[-]}\end{array}$ & $\dot{m}_{f}[\mathrm{~kg} / \mathrm{s}]$ & $N$ & $F^{\prime}(\tau \alpha)_{e n}$ & $F^{\prime} U_{L}$ & $\tau_{C}[\mathrm{~s}]$ & $F^{\prime}(M c)_{e}$ \\
{$[-]$} & {$\left[\mathrm{W} /\left(\mathrm{m}^{2} \mathrm{~K}\right)\right]$} & & {$[\mathrm{J} / \mathrm{K}]$} \\
\hline 0.927 & 0.030 & 60 & 0.521 & 11.731 & 600 & 36,180 \\
\hline
\end{tabular}

Note: $c_{1}=0.000524, c_{2}=0.0118, \quad c_{3}=0.988$ 
Table 2 Collector characteristic parameters determined by the steady-state test (Deng et al., 2016a)

\begin{tabular}{ccccccc}
\hline $\begin{array}{c}A_{a} / A_{g} \\
{[-]}\end{array}$ & $\dot{m}_{f}$ & $F_{R}(\tau \alpha)_{e n}$ & $F^{\prime}(\tau \alpha)_{e n}$ & $F^{\prime} U_{L}$ & $\tau_{C}[\mathrm{~s}]$ & $F^{\prime}(M c)_{e}$ \\
\hline 0.927 & 0.030 & 0.379 & 0.529 & 11.749 & 607 & 36,847 \\
\hline
\end{tabular}

